\title{
MANIFESTO DOS PIONEIROS VERSUS MANUAL DIDÁTICO DE LITERATURAS ESTRANGEIRAS: IGREJA CATÓLICA FRENTE À REVOLUÇÃO ESCOLANOVISTA
}

Maria Lucia de Amorim Soares Universidade de Sorocaba/SP maria.soares@prof.uniso.br

Eliete Jussara Nogueira Universidade de Sorocaba/SP eliete.nogueira@prof.uniso.br

Luiz Fernando Gomes Universidade de Sorocaba/SP luiz.gomes@prof.uniso.br

Leandro Petarnella

Universidade Nove de Julho/SP leandro@uninove.br

\section{RESUMO}

Este trabalho tem como objetivo explicitar, através da análise do Manual Didático de Literaturas Estrangeiras, de autores anônimos, publicado em 1931 pela editora FTD, do Rio de Janeiro, a existência de convicções católicas exasperadas pelo clima espiritual e pelo contexto histórico da época. Essa publicação que atende às diretrizes emanadas do papado, responde às modificações estruturais da Igreja-Estado e reage às discussões dos escolanovistas que, inspirados pela pedagogia ativa da "educação pela ação" do americano John Dewe, lutavam em prol de uma escola publica, gratuita, obrigatória e laica. Por meio desse curioso manual, as escolas católicas do Rio de Janeiro recebiam avaliações polêmicas baseadas no pensamento de direita da Igreja, com advertências sobre a suposta perversidade existente em obras de romancistas, poetas, filósofos, historiadores alemães, ingleses, russos, franceses e portugueses. Os resultados da análise conduzem à afirmação de que o momento no qual estruturas tradicionais convivem e conflitam com novas forças emergentes, (Era Vargas 1930-1934), o acirramento ideológico leva a uma reação daqueles pertencentes à Igreja Católica no âmbito escolar.

Palavras-chave: Escola Nova. Pensamento Católico. Manifesto dos Pioneiros. Literaturas

Estrangeiras.

\section{MANIFEST OF PIONEERS VERSUS DIDACTIC MANUAL FOR FOREIGN LITERATURE : THE CATHOLIC CHURCH AND THE ESCOLANOVISTA REVOLUTION}

\begin{abstract}
This paper aims to explain, by examining the Manual Didático de Literaturas Estrangeiras, by anonymous authors, published in 1931 by FTD, Rio de Janeiro, the existence of Catholic beliefs exasperated by the spiritual climate and the historical context of the time. This publication that meets the guidelines issued by the papacy responds to structural changes in the church-state and react to discussions of escolanovistas who, inspired by the
\end{abstract}


active teaching of "education for action" of the American John Dewe, fought on behalf of a public school, free and compulsory. Through this curious manual, the Catholic schools of Rio de Janeiro received controversial assessments based on the thinking of the right of the Church, with warnings about the supposed evil that exists in works of German, English, Russian, French and Portuguese novelists, poets, philosophers, and historians. The results of the analysis lead to the claim that the time in which traditional structures coexist and conflict with new emerging forces (Vargas Era 1930-1934), the ideological incitement leads to a reaction of those belonging to the Catholic Church in school.

Keywords: Escola Nova. Catholic thought. Manifest of the Pioneers. Foreign Literature.

Com a República, em 1889, e a conseqüente separação formal entre a Igreja e o Estado, a organização eclesiástica brasileira foi obrigada a recompor-se em novos patamares para rapidamente criar os mecanismos necessários para ocupar os aparelhos ideológicos do Estado, em particular o escolar:

Ademais, a educação fora laicizada, a religião fora eliminada dos currículos, e os governos federal e estaduais, estavam proibidos de subvencionar escolas religiosas. Nada disso, entretanto, impediu que a prestação de serviços educacionais para elites passasse a constituir a diretriz-mor da política expansionista seguida pela organização eclesiástica.(MICELI, 1988, p. 23).

Nota-se uma grande fecundidade de textos divulgados na época, destinados a orientar os fiéis sobre como se portarem diante dos novos fatos. A Igreja, atribuindo-se o papel de Mestre dos Povos, refuta acusações de que não privilegiava a educação. Dom Antonio dos Santos Cabral, Arcebispo de Belo Horizonte, sintetiza essa questão em sua Carta Pastoral A Igreja e o Ensino: Inconsistente é a argüição da impiedade, inspirada na mais revoltante má fé, acoimando-a de inimiga systhemática das luzes, e de haver conspirado sempre contra a instrução, para manter o povo sob o jugo da superstição. (CABRAL, 1925, p.05).

Dom Octávio Pereira de Albuquerque (1915, p.11), Bispo do Piauí, em sua Segunda Carta Pastoral Sobre o Seminário e Collégios Diocesanos, demonstra em 1915, que o episcopado brasileiro ainda lutava para reaver seu status quo:

Pois bem, nobres patrícios, Nós vos oferecemos um remédio efficaz a todos esses males, que tanto prejudicam a tranqüilidade de vosso governo e a felicidade da Pátria! Quereis saber qual será? É a volta do Brasil estado à essa santa Religião Católica, Apostólica, Romana, que, por séculos inteiros, operava a nossa ominimoda felicidade; só assim governareis tranqüilamente e recebereis do povo as demonstrações de respeito a que tendes inconcluso direito no exercício da nossa autoridade.

A Igreja Católica resistia, também, `as freqüentes acusações de ser representante do obscurantismo e de constituir-se em baluarte na luta contra a universalização do ensino propugnada pelo liberalismo. Segundo Pio X (1944, p. 964)I:

A educação cristã da juventude, dificultada e às vezes descuidada, aí como em outras nações, está agora seriamente comprometida por erros contra a fé e a moral e por calúnias contra a Igreja, a qual se apresenta como inimiga do progresso, da liberdade e dos interesses do povo. 
Em 1907, o papa Pio X, em sua encíclica Pascendi Domini Gregis havia afirmado ser dever dos bispos cuidar dos escritos dos modernistas ou que conhecem o modernismo ou o promovem, se têm sido publicados, não sejam lidos, e se não o houvessem sido, não se publiquem (1944, p. 288), conforme coloca Elomar Tambara, em reunião da ANPED/ Caxambú (BR), em 2005.

É nesse sentido que a hierarquia católica brasileira publica, entre outros, o Manual Literaturas Estrangeiras, pela FTD, no ano de 1931. Essa publicação vem em consonância com as diretrizes emanadas do papado e responde às modificações estruturais da Igreja Estado ocorridas a partir da Proclamação da República. Contextualiza-se no momento histórico da Revolução de 30 e nas discussões dos escola - novistas, inspirados na pedagogia ativa da "educação pela ação" do americano John Dewey, em prol de uma escola pública, gratuita, obrigatória e laica que constituía uma antiga reivindicação do liberalismo burguês.

\section{O Advento da Escola Nova}

A Primeira Guerra Mundial marcou, na realidade, o fim do século XIX e o princípio do século XX. Foram decisivas suas conseqüências econômicas, sociais e políticas. Num mundo profundamente abalado e transformado, o conceito de educação não podia deixar de ser alterado. A Escola Nova, com suas interpretações americanas, francesas, alemãs, italianas e russas, não podia ficar estranha aos educadores brasileiros, que despertavam para a ideia nacionalista, já invocada em 1890 por José Veríssimo, na sua obra A Educação Nacional, e agitada publicamente pelo poeta Olavo Bilac. Na imprensa, Antonio Leão trazia os problemas que eram discutidos no estrangeiro, estudando-os à luz das realidades brasileiras, explicitando-os com rigor quando publicou $O$ Brasil e a educação popular ${ }_{2}$ em 1917 (p.35):

[...] ainda vivemos nos tempos de esperar milagres. Supomos que nossa fortaleza se fará com decretos e medidas de economia se o povo continuar o mesmo, se perseveramos na mesma falta de capital e trabalho, se não há iniciativa, se a aspiração nacional pela burocracia não descontinua um momento.

De um modo geral, a preocupação com a educação pode ser interpretada como a manifestação do desejo de construir uma unidade fundamental para a nação. Homens novos para tempos novos, dizia Fernando de Azevedo, em 1926. [...] Aplicar as medidas mais apropriadas para que a educação responda positivamente aos ideais sociais [...] ampliava Fernando de Azevedo, em 1931. Sob este aspecto não foi o movimento de idéias, mas foram homens os responsáveis pelas reformas no ensino, tendo um objetivo nítido: criar um sistema de educação concebido para a preparação eficaz da criança ao trabalho produtivo e atender às necessidades daquilo que esses intelectuais classificavam como um povo em formação. Ou seja, tratava-se de um sistema de educação capaz de assegurar a coesão política e consolidar a composição étnica homogênea do brasileiro. Um meio de ajustar os homens às condições e valores da vida moderna, determinados na sua finalidade: civilizar.

Dados os primeiros impulsos, sucederam-se a criação de obras relativas à educação que envolviam questões de psicologia, de testes, de sociologia urbana e rural, de métodos de ensino e processos de aprendizagem, acompanhando um ciclo de reformas inspirado nos ideais escola - novistas em quase todos os Estados. No cerne do modelo de escolarização que se implantava, os educadores responsáveis foram Sampaio Doria (1920, São Paulo), Lourenço Filho (1922, Ceará), Anísio Teixeira (1924, Bahia), Carneiro Leão (1928, 
Pernambuco), Lisímaco da Costa (1927, Paraná), Francisco Campos (1928, Minas Gerais) e Fernando de Azevedo (1928, Distrito Federal).

O novo para Fernando de Azevedo, tal como aparece caracterizado permeando os capítulos de seu livro A Cultura Brasileira, tem três acepções básicas para Marta Carvalho (1998, p. 22-23):

$\left.1^{a}\right)$ permeabilização do país aos valores culturais da Europa e dos Estados Unidos do pós-guerra, com destaque especial para as reformas educacionais com que se sonhava forjar uma humanidade nova em que se concentravam as últimas esperanças de uma vida melhor, da restauração da paz pela escola e da formação de um novo espírito, mais ajustado às condições e necessidades de um novo tipo de civilização;

$2^{a}$ ) adaptação do sistema escolar às exigências de uma sociedade nova, de forma industrial, em franca evolução para uma democracia social e econômica, sem que fosse descurada condições específicas do meio social brasileiro, ainda não profundamente atingido pelos efeitos da revolução industrial;

$3^{a}$ ) unificação do sistema educacional em nível nacional por uma política orgânica traçada pelas elites governantes, em outros termos, o que era entendido por uma política nacional de educação.

Estas três acepções disseminadas pelo texto de Fernando de Azevedo (1943) entrecruzaram-se de forma a enfeixar o significado do movimento ascensional do novo naquilo que é referido como mancha resoluta para uma política nacional de educação (p. 385) cujo objetivo principal seria minar o papel dos sistemas estaduais educativos na conservação e difusão de tipos de ensino tradicionais e das velhas culturas (p. 389), abrindo caminho para uma escola que, identificada com os valores da nova sociedade urbano-industrial que se constituía, e permeada por valores culturais estrangeiros, viesse a atuar nacionalmente, direcionada pelo Estado, como instância de renovação e de democratização social.

Em 1932, vinte e seis educadores expuseram publicamente suas concepções através do Manifesto dos Pioneiros, denominação pela qual ficou conhecido, publicado na revista Educação, vol. 6, n. 1/2/3 (jan./fev./mar 1932), sob o título A reconstrução educacional no Brasil: ao povo e ao governo, documento que revela os pontos que os reformadores defendiam para a educação como resposta para o mundo em transformação. O texto introdutório aponta que a indisciplina social e mental, manifestação da crise tremenda que atravessa a civilização (p. 9), tenderia aqui a agravar-se:

Ora, num povo ainda em formação como nosso, sem lastro de tradição e de cultura, e constituído de grupos sociais, móveis e dispersos, sem coesão e sem vida coletiva, a "indisciplina social e mental", que caracteriza a nossa época, tinha a agravar-se sob a pressão dessas condições particulares.

Em vista dessas condições particulares (p.27), os reformadores defendiam uma proposta pedagógica com base em conceitos de progresso e desenvolvimento que influiriam na formação uniforme das mentalidades, para tanto determinando uma definição nítida do papel da escola na sociedade, assim formalizada:

Mas, essa consciência largamente compreensiva da multiplicidade dos fatores sociais que intervêm no desenvolvimento da criança, "socializando-a progressivamente", por isso mesmo que dá uma noção nítida do papel da escola na sociedade, cria a consciência da necessidade 
de se alargar continuamente o campo da escola (das influências diretas ou mediatas), para contrabalançar as que se exercem fora de toda intervenção consciente dos órgãos especiais de educação (p. 27).

O texto da introdução deixava claro que elaborar um programa completo de reconstrução educacional implicava uma tarefa de intervenção de elites tecnicamente preparadas para isso, ou seja, órgãos especiais de educação (p. 24). Os órgãos referidos eram os grupos intelectuais que preparavam o Manifesto, cujo traço comum entre a maioria dos signatários era o fato de exercerem função legada ao magistério.

O Manifesto propriamente dito trazia o título A reconstrução educacional no Brasil: ao povo e ao governo. A parte inicial traz considerações sobre diretrizes e finalidades da educação. Primeiro lembra que a educação era problema nacional ao constatar que não lograram ainda criar um sistema de organização escolar à altura das necessidades modernas e das necessidades do país (p. 33). O problema era atribuído à falta de determinação dos fins da educação e da aplicação dos métodos científicos aos problemas da educação.

Cecília Mate (2006, p. 26) explicita que é no item Diretrizes que se esclarece o Manifesto, lugar onde constam o papel e a necessidade de direcionar a efervescência intelectual gerada no professorado, a partir do movimento renovador, que, incutido no gosto pela crítica e pelo debate, precisava ser conduzido por caminhos definidos:

\begin{abstract}
A maioria dos espíritos, tanto na velha como na nova geração ainda se arrastavam, porém, sem conviç̧ões, através de um labirinto de idéias vagas, fora de seu alcance,e certamente acima de sua experiência; e, porque manejam palavras, com que já se familiarizaram, imaginam muitos que possuem as idéias claras, o que lhes tire o desejo de adquirilas... Era preciso, pois, imprimir uma direção cada vez mais firme a esse movimento já agora nacional, que arrastou consigo os educadores de mais destaque, e levá-los a seu ponto culminante com uma noção clara e definida de suas aspirações e suas responsabilidades.
\end{abstract}

Criticando a "educação tradicional" como verbalista e dirigida a uma classe social economicamente privilegiada, portanto presa ao interesses de classe, o Manifesto diz que a educação deixa de constituir um privilégio determinado pela condição econômica e social do indivíduo, para assumir um "caráter biológico", como que ela se organiza para a coletividade em geral [...](p.42), função social a ser realizada pelo Estado com a cooperação de todas as instituições sociais (p.45), numa escola que se estenderia como escola oficial, única, em que todas as crianças de 07 a 15 anos teriam uma educação comum, igual para todos.

A questão da laicidade, gratuidade, obrigatoriedade e coeducação é colocada, com ênfase, no primeiro tema de Manifesto - O Estado em face da educação, sendo que a defesa da laicidade coloca o ambiente escolar acima das crenças e disputas religiosas (p. 48), tornando-se uma questão polêmica porque tal afirmação reforçava a idéia de ruptura dos renovadores com a ordem tradicional, o monopólio das idéias pedagógicas pelos católicos, uma vez que a perspectiva de gratuidade e obrigatoriedade do ensino vinculou-o ao Estado, única instância em condições de assumir sua extensão.

Ressignificada como instrumento de reforma moral da sociedade e administrada a partir de um projeto nacional, a escola vai tornar-se espaço de experimentos e estudos, onde novas teorias serão testadas na busca de formas mais eficientes dos desejáveis comportamentos e hábitos enquanto modernizadores da sociedade. Os católicos 
manifestam-se contra esse processo, principalmente em relação ao combate à circulação daquilo que considera livros perniciosos à boa formação do cristão.

\section{O Manual Literaturas Estrangeiras}

Durante o período colonial (1500-1822), o imperial (1822-1889) e na maior parte da República Velha (1889-1930) a ideologia econômica dominante, informava que o Brasil era um país de vocação agrária, produtos de gêneros agrícolas tropicais de exportação e consumidor de produtos industrializados estrangeiros. Esse quadro manteve-se até os finais da República Velha, quando $72,5 \%$ de nossa receita de exportação provinha unicamente do café (1924-1928) apesar das freqüentes crises de superprodução que obrigava o Governo a intervir na política de valorização artificial dos preços desse produto. Com a crise econômica mundial de 1929, não foi possível obter empréstimos externos para a manutenção dessa política fazendo os preços desabarem, contribuindo para o rompimento político entre os principais setores da oligarquia tradicional. O desfecho desse processo foi a Revolução de 1930, liderada por Getúlio Vargas, que ao assumir o poder, abriu espaços para a manifestação das novas forças políticas que se formavam no país: empresários industriais, os militares, as classes médias urbanas e o proletariado industrial. Muitos interesses estavam em jogo e esses interesses determinavam forte pressão para a implementação de novas e diferentes oportunidades educacionais, que vão concretizar-se com o pensar e a criação da chamada Escola - Nova, conforme demonstrado anteriormente.

Munida dos argumentos recolhidos nas obras do pensamento contra-revolucionário e nos documentos oficiais de catolicismo, que davam coerência á pretensão do reordenamento social em bases religiosas, a Igreja Católica oferece reação às tendências oficiais e à ideologia dos renovadores. Em 1931, as escolas católicas do Rio de Janeiro eram orientadas no sentido de adotar um manual intitulado Literaturas Estrangeiras, de autoria coletiva, anônima, publicado sob a responsabilidade da editora Fréres Theodore Dumont - FDT. Em robustas 660 páginas, a obra fornecia breves informações sobre os escritores, avaliando-os de acordo com os critérios fixados pelo pensamento de direita no interior da Igreja.

Literaturas Estrangeiras é um manual polêmico, com advertências contundentes para a perversidade existente em obras de romancistas, poetas, filósofos, historiadores alemães, ingleses, russos, franceses e portugueses. Um pequeno artigo, publicado no Caderno Idéias, do Jornal do Brasil (25/08/2007, p. 9), transcreve algumas caracterizações realizadas pelos autores anônimos:

Voltaire é caracterizado como "corifeu da impiedade no século 18. Em decorrência dos "erros satânicos", que cometeu, seu talento, embora reconhecido, deve ser considerado "de memória execranda". Stendhal é visto como um romancista "materialista e imoral". Victor Hugo é a "personificação do espalhafato". Uma das condenações mais drásticas é feito ao poeta Baudelaire: "cheio de miasmas, pestilências, de sujidades físicas e morais. Nojento. Dirige preces a Satanás. Desequilibrado".

O poeta Rimbaud, considerado vagabundo, "Luta contra Deus, é ímpio, romântico e naturalista. Quebra-Louça. Deus lhe Quebra o corpo" (p. 431). Émile Zola, pernicioso, é mestre da pornografia" (p. 427). Verlaine, boêmio, cínico, amigo de Rimbaud, é "mendigo perpétuo de volúpias, dinheiro, idéias e bebedeira” (p. 428). Rabelais, monge apóstata, médico desmiolado e pasta de canalha, "tem a mania da obscenidade" (p. 428). Anatole France, corruptor diabólico, é "ímpio e imoral até o cinismo" (p. 428). Flaubert, incrédulo 
e desabusado, é criticado por se preocupar com o estilo: "De moral e religião cuidava menos, já se vê" (p.425). No verbete de Proust se lê: "De raça judaica. Franzino $e$ enfermo, fez uma obra literária judaica e enfermiça. A mentalidade pouco normal".(p. 456). A respeito do poeta Apollinaire, informa que ele tinha "mãe polaca" e foi "trepanado na guerra", em 1916 (p.453).

Os escritores alemães também sofrem a fúria dos críticos em Literaturas Estrangeiras (1931). Sobre Hegel: "Ensina a identidade dos contrários. Nega os princípios mais elementares da razão" (p.595). Schopenhauer era "neurastênico, zangadiço, ranzinza. Só gostava de si próprio” (p.597). O poeta Heine, nascido judeu e convertido ao protestantismo "vilipendiou a Igreja, a sociedade, a pátria, a virtude. Acabou cego, paralítico, desgostoso. Oito anos de agonia" (p.597). Nietzsche, filósofo teorista do superhomem, "blasfema grosseiramente Cristo e sua Igreja. Dá-se mesmo pelo Anticristo. Acabou doido" (p. 599).

Oscar Wilde, jocoso, escandalizou a Inglaterra a assumir sua homossexualidade, no final do século XIX, lançando "à sociedade um desafio insolente e ela o esmagou" (p.568). O poeta Byron, ardente, violento, original, cocho, era "um fanfarrão do vício, do escândalo e do cinismo" (p. 568). James Joyce em Ulisses exibe a "mania da cloaca. Desde Rabelais, nada houve mais nojento. Até a maternidade, Joyce a profanou” (p. 571). $\mathrm{O}$ russo Gorki, detestoso menino desorientado, de sensibilidade anormal, é um "apologista da vagabundagem, dos assassinos, dos bandidos, dos malandros, dos contrabandistas. Fez sucesso devido a novidade" (p. 616). Leon Tolstoi, excomungado, é um "hipócrita fauno convertido", conforme dizia o "famigerado Lênin" (p.615).

Como Émile Zola era pernicioso, mestre da pornografia, sua influência sobre Eça de Queiroz - o "Zola Portuguez" - torna as obras, de ambos, indignas de serem lidas por homens de bem e homens de fé. (p. 260). O manual transcreve a apreciação de José Agostinho, crítico lusitano, sobre Eça de Queiroz: Eça parecia profundamente egoísta e até autólatra... como o confessa elle próprio, estava desnacionalizado no espírito e no sentimento... descrição de requintes viciosos, pessimismo sistemático, afrancesamento lamentável da língua ... Outros têm sustentado que a obra de Eça é essencialmente immoral e sceptica (p. 256).

Eça de Queiroz e o poeta Guerra Junqueiro eram os autores mais lidos, mormente pela juventude, no Brasil. (p. 546). Se Eça usava de sarcasmos excessivos e satânicos, o conjunto da obra de Guerra Junqueiro é essencialmente mau, incoerente e anti-humana (p.265). Serafim Leite diz: Poucos escritores terão concorrido tanto como Guerra Junqueiro para o mal estar social de que enferma nossa pátria; com suas oratória rebuscada e hypocrita, Guerra Junqueiro, estranho, como Judeu, a todos os nossos instintos de honra, não hesita em polluil-o como um boneco de feira, que se maneja à vontade... nós que somos de boa christantade, sem mistura de sangue condennado, chamando-lhe simplesmente o que ele é: JUDEU! (p. 267). Vieira de Almeida resume os juízos que o manual apresenta: [...] eu teria de rejeitar Junqueiro "EM BLOCO", e devo dizer sem hesitação. Pouco se perdia comparado com o que se ganhava. Rejeitava-se uma filosofia de mestre-escola, uma estética de tamborileiro, uma ôca ênfase de retórico, um estilo de rã assoprada, e no turbilhão envoltos, uma dúzia si tanto, de versos bem feitos. $O$ lucro seria grande. (p. 269).

Entre outras numerosas apreciações existentes no manual, dada a impossibilidade de aqui serem trabalhadas, o fechamento chega com a filiação de Aquilino Ribeiro à Anatole France, francês ímpio, moral até o cinismo, corruptor diabólico, nefando, que faz dele, Aquilino, mesmo sendo fino lavrante - o celline da Prosa, um autor satânico, de 
linguagem grosseira, discípulo atrasado do naturalismo, francamente materialista, no dizer de Tristão de Athayde (p. 311). Este, ocupava a liderança da intelectualidade católica, ligado ao católico Centro Dom Vital, fundado em 1922, tendo como principal meio de divulgação a Revista A Ordem, que postulava a idéia de que $O$ Estado compreenda todo seu dever para com o ideal cristão de uma nacionalidade formada espiritualmente pelo catolicismo e que só este pode desenvolver. (ATHAYDE, 1931, p. 67).

\section{Palavras Finais}

Os resultados da análise do Manual Literaturas Estrangeiras conduzem à afirmação de que no momento no qual estruturas tradicionais conviviam e conflitavam com novas forças emergentes, o acirramento ideológico levou à uma reação peremptória daqueles pertencentes à Igreja Católica que diz ser a única que respeita a moral mais rigorosa pelo culto a Deus, à Pátria e à Família. Veemente, um prefácio conclama a escutar conselhos dos autores: "Eu quizéra ter uma voz forte e retumbante para que se ouvisse no Brasil inteiro e em todo Portugal, para gritar aos ouvidos das gerações que surgem: não desprezeis as obras da FTD; elas vos ensinarão, a-par-da ciência necessária para vencerdes na vida, os meios mais adequados para chegardes á região da eterna felicidade!". Nesse sentido, é compreensível concluir afirmando não ser possível esquecer conflitos históricos e relações de poder em projetos educacionais em disputa, já que as palavras têm história, são polissêmicas, contextuais, organizam-se de certas maneiras no discurso e, desse modo, ordenam as coisas do mundo. Entretanto, mais do que nas palavras é preciso prestar atenção em quem as diziam: intelectuais combativos, dispostos a defender seus dogmas, suas crenças, em consonância com a extrema direita da Igreja Católica.

A preocupação de ajustar a diferenciação e a qualidade do ensino aos requisitos de uma civilização urbano-industrial, e também o anseio de considerar a produção intelectual dos educadores, em particular a resultante da pesquisa científica, a serviço de um sistema de educação pública, deu importância às reformas da instrução. Sob a designação de escola nova, tanto as preocupações quanto os anseios daqueles que participaram das campanhas de renovação educacional encontraram uma valência comum. Ela foi feita toda na aproximação de intelectuais identificados com o movimento de inovação educacional e professores interessados nessa renovação: é dizer que se estruturou ao redor de alguns grandes temas e de alguns nomes destacados. Nesse sentido, o que significava produção intelectual, as reformas da instrução e os movimentos de reorganização de instituições escolares, técnicas e administrativas consolidaram mais que um projeto definido de ação educativa, um sistema de alianças públicas. (PAULILO, 2003). Nesse sentido o Manifesto de 32, significou, em educação, a política nacionalizante dos anos 30, como amalgamou as ideias dos renovadores em um documento de força retórica e projeção política.

Em um ambiente de profundas discussões, que angariou muitos debates, a Igreja Católica vai colocar seus dogmas em oposição ao cientificismo ideológico. Segundo Beozzo(1986,p. 280):

Consumada a separação entre Igreja e Estado, a Igreja não cessará de denunciar o divórcio entre o Estado leigo, para não dizer laicista, e a nação católica, em sua grande maioria. O ensino era visto como uma grande violência imposta à consciência católica. Seu caráter leigo conflitava com a fé da maioria dos alunos e com a fé professorada pela nação. 
Nesse itinerário, os autores anônimos do Manual Literaturas Estrangeiras não eram loucos desvairados, conforme apreciação do autor, também anônimo, do artigo Sectarismo e Franqueza, publicado no Caderno Idéias, do Jornal do Brasil (25/08/2007, p.09):

[...] liam atentamente os livros que comentavam, em consonância com a extrema direita da Igreja Católica. Eram intelectuais combativos, dispostos a defender seus dogmas, suas crenças. Estavam atualizados. Citavam Tristão de Ataíde, Agripino Grieco, Tasso da Silveira, Jackson de Figueiredo.

A finalidade da educação se define com a filosofia de cada época, diz o Manifesto dos Pioneiros da Educação Nova (ROMANELLI, 1980, p. 146). Engels, prefaciando $O 18$ Brumário de Luís Bonaparte de Marx (1978:327), expõe a importância da compreensão da história viva de uma época, visto que é a história que nos ajudará a entender a educação:

Essa notável compreensão da história viva da época, essa lúcida apreciação dos acontecimentos ao tempo em que se desenrolaram, é, realmente sem paralelo. Mas para isso era preciso ter o profundo conhecimento que Marx possuía da história francesa. A França é o país onde, mais do que em qualquer lugar, as lutas de classe foram sempre levadas á decisão final, e onde, por conseguinte, as formas políticas mutáveis nas quais se processam essas lutas e nas quais se condensam seus resultados tomam os contornos mais nítidos... Esta foi a razão pela qual Marx não só estudou a história anterior da França com especial predileção, como acompanhava também sua história contemporânea em todos os detalhes, reunindo materiais destinados a futura utilização.

Com referência às Literaturas estrangeiras, reafirmamos que, mais do que às palavras, é preciso prestar atenção a quem as diz. No texto em questão, aos intelectuais da Igreja Católica frente aos escolanovistas na década de 20/30, do século XX.

\section{Referências}

ALBUQUERQUE, O. P.. Sobre o Seminário e Collégios Diocesanos. Terezina: Typografia, P. 1915. (2 $2^{\mathrm{a}}$ Carta Pastoral)

ATAHYDE, T.. Debates pedagógicos. Rio de Janeiro: Schimidt, editor, 1931.

AZEVEDO, F.. A cultura Brasileira. Rio de Janeiro: Serviço Gráfico do IBGE, 1943.

A educação pública em São Paulo: problemas e discussões para “O Estado de São Paulo", em 1926. São Paulo: Editora Nacional, 1937.

Novos caminhos e novos fins: a nova política de educação no Brasil. São Paulo: editora Nacional, 1931.

BEOZZO, J. O.. A Igreja e a revolução de 1930. In: FAUSTO, Boris (Org.). História Geral da Civilização Brasileira. Tomo III, 4º vol. São Paulo: Difel, 1986.

CABRAL, A. S.. A Igreja e o Ensino. Belo Horizonte: Imprensa Diocesana, 1925 (Carta Pastoral).

CARNEIRO LEÃO, A..O Brazil e a educação popular. Rio de Janeiro: Typ. do Jornal do Commercio, 1917.

CARVALHO, M. M. C.. Molde Nacional e Forma Cívica. Bragança Paulista, SP: EDUSF, 1998. 
Carta Pastoral do Episcorajado Brasileiro (1900). In: A Igreja na República: Brasília: UNB, 1981.

EDUCAÇÃO. Órgãos da Diretoria Geral da Instrução Publica de São Paulo. V.6, n.1/2/3, jan./fev./mar.1932.

Literaturas Estrangeiras. Rio de Janeiro: FTD, 1931.

Manifesto dos Pioneiros. Revista da Educação, n6,n.1/2/3 (jan/fer/mar), 1932.

MARX, K.. O 18 Brumário de Luis Bonaparte. São Paulo: Abril Cultural, Coleção os Pensadores, 1978.

MATE, C. H.. O Manifesto dos Pioneiros de 32 como ampliação da política reformista. Caxambu: GT02, História da Educação, ANPED, 2006.

MICELI, S.. A Elite Eclesiástica Brasiliense. Rio de Janeiro: Bertrand, 1988.

PAULILO, A. L.. Revista Brasileira de História. São Paulo, v. 23, nº 46, pg. 93 - 122, 2003.

PIO XI. Carta ao Episcopado Filipino. In: Colecion de Encíclicas y cartas Pontifícias. Buenos Aires: Editorial Pablet, 1944.

PIO X. Pascendi Dominici Gregis. In: Colecion de Encíclicas e Cartas Pontifícias. Buenos Aires: Editorial Poblet, 1944.

ROMANELLI, O. O.. História da educação no Brasil(1930-1973).

Sectarismo e Franqueza. Caderno Idéias, Jornal do Brasil, 25/08/2007, p. 9.

TAMBARA, E.. Estado, Igreja e Educação - Urbi et Orbe. Caxambu: GT História da Educação / n. 02, ANPED, 2005. 